\title{
Organizational and technological solutions of multicriteria quality analysis in high-rise construction
}

\author{
Aida Mirzakhanova ${ }^{1 *}$, Muhammad Khalil ${ }^{1}$, Natalya Galaeva ${ }^{1}$, Ruben Kazaryan ${ }^{1}$ \\ Moscow State University of Civil Engineering, 26 Yaroslavskoe shosse, Moscow, 129337, Russia
}

\begin{abstract}
Features of renovation of built-up areas are considered. The main difficulties in carrying out the renovation process are identified. The concept of the constraint factor of the building is defined. Methods. A method for analyzing and assessing constraints for selecting optimal organizational and technical solutions for the renovation of territories is proposed. Results. An analysis algorithm is proposed, based on the consideration of the constraint factor as an array of actions of individual "objects of influence" on the corresponding "subjects of influence". Conclusion. Conducting such an analysis will provide the most effective and optimal organizational and technological solutions reflected in the relevant sections of the renovation project in high-rise construction (development of a construction master plan, preparation of calendar and network work schedules). The implemented rational version of the design solution ensured the reduction of the prime cost and the reduction of the terms of the preparatory works for the renovation of housing construction projects taking into account seismic uncertainty. Renovation is one of the varieties of this reconstruction of high rise construction.
\end{abstract}

\section{Introduction}

According to the proposal of Vedeneev N.S. and Maklakova T.G. the term "renovation" and its definition of renovation is the compulsory release of the territory to ensure the possibility of new construction, regardless of the degree of safety of the buildings located on it. The term was applied to the construction reconstruction by Resin V.I. in the directive documents of the Government of Moscow. In the theory of reorganization and the basic cycle of reorganization, the reorganization is considered as one of four successive stages [1, 2,3 , etc.], regulated by the rules of production [4].

Currently, Moscow is implementing a program for the renovation of individual residential areas. This program replaced the bad experience of spot-building.

The main difference between the renovation projects is their complexity, which means a complete demolition of housing stock, replacement of communications, repair of roads, reconstruction of infrastructure and landscaping [5].

According to Moskomarkhitektura [6], over $45 \%$ wear has more than $14 \%$ of the city's

* Corresponding author: mirzahanova-aida@rambler.ru 
housing stock. For this part of the fund, the physical depreciation index reaches 55\%, which leads to additional costs for maintaining this housing, lowering the comfort level of living and requires the adoption of program measures for the renovation, reconstruction and renovation of existing housing.

The moral and physical deterioration of buildings and communications, the lack of space for new construction and the requirements for more efficient use of the territory - all this contributes to the development of a renovation program, enabling in the near future to take a modern look to many of the "aging" quarters of the city. The purpose of the study was to identify the specifics of organizational and technological solutions for renovating urban areas in constrained conditions. Attempts to address this problem were made more than 10 years ago [7], but at that time they did not find understanding in the administrativecommand layer of the Moscow leadership. Today, the implementation of this task is one of the most important socio-economic and strategic goals of the city-planning policy of the Moscow government.

\section{Methods}

Both the domestic researchers studied the problems of designing the technology and organization of building reconstruction and reconstruction of buildings and structures (Baranovsky A.V., Zolotnitsky N.D., 1948; Gendel E.M., 1958; Onufriev N.M., 1965; Bolshakov V.A., Rogonsky V.V., 1966; Kolotilkin B.M., 1969; Gusakov A.A., Polyakov E.V., 1972; Okon I.P., 1973; Budanova N.P., 1974; Titova I.A., 1975; Ignatyuk M.S., Prokhorkin S.V., 1976; Ganiev K.B., 1977; Dmitriev M.N., Poryvay G.A., 1979; Lapshin E.I., 1982; Balk V.A., Dzhalilov F.F., 1985; Belyakov Yu.I., Redunik A.F., Fedoseenko N.M., 1986; Bytko A.I., Frolkin V.T., 1987; Sedikh S.V., Frosin A.V., 1988; Karsky N.Z., Ivanov R.T., 1989; Abramov L.I., Manaenkova E.A., 1990; Bolotov V.P., Sataev A.G., 1991; Bondar F.I., Yurkin N.M., 1992; Zelentsov L.B., Lazarev G.I., 1993; Biryukov G.S., Plebukh A.N., Chulkov V.O., 1994; Beyer V.E., Belov A.N., Sardaryan T.G., 1995; Bashmakov A.N., Rakhimov K.D., 1996; Alekseev Yu.V., Aripjanov A.A., Zakharov V.A., 1997; Afanasyev A.A., Mokhov A.I., 1998; Semechkin A.E., 1999; Burdacheva N.A., 2000; Ivaschenko A.I., 2001; Veykum I.I., 2001; Ovchinnikov S.G., 2002; Kuznetsov S.V., 2003; Golubeva N.N., 2004 and others) and foreign experts. They proved that the development of projects for building reconstruction is much more complicated than the design of new construction: multiple additional measurements and surveys of the reconstructed buildings and their premises are necessary, an examination of the suitability of structural elements and individual structures, a study of the layout of schemes of various types of engineering communications, etc.

The studied destabilizing factors were ranked from the most significant ones to the least significant ones in accordance with the statistical analysis adopted in the questionnaire (figure 1). The following conceptual provisions are suggested for research in the above areas of management: management - always a human activity, in which goals and interests play a decisive role; management is diverse and multivariate, therefore it is impossible to reduce it to any single option, no matter how perfect this option may seem; management has two interrelated aspects of functioning: socio-economic and organizational-technical; management is built on the desire for harmony (coordination, organization, etc.), but it is the harmony of balance, the harmony of contradictions, combination, and not the harmony of absolute stability, homogeneity, sameness or uniqueness. Substantive and effective management is always the result of the manager's preliminary thought activity, his ability to show the volume and structure of his knowledge, his predisposition to cognition, to the development and improvement of his thinking. According to priority areas of knowledge 
used in thought activity, thinking is conditionally divided into humanitarian, mathematical and technocratic

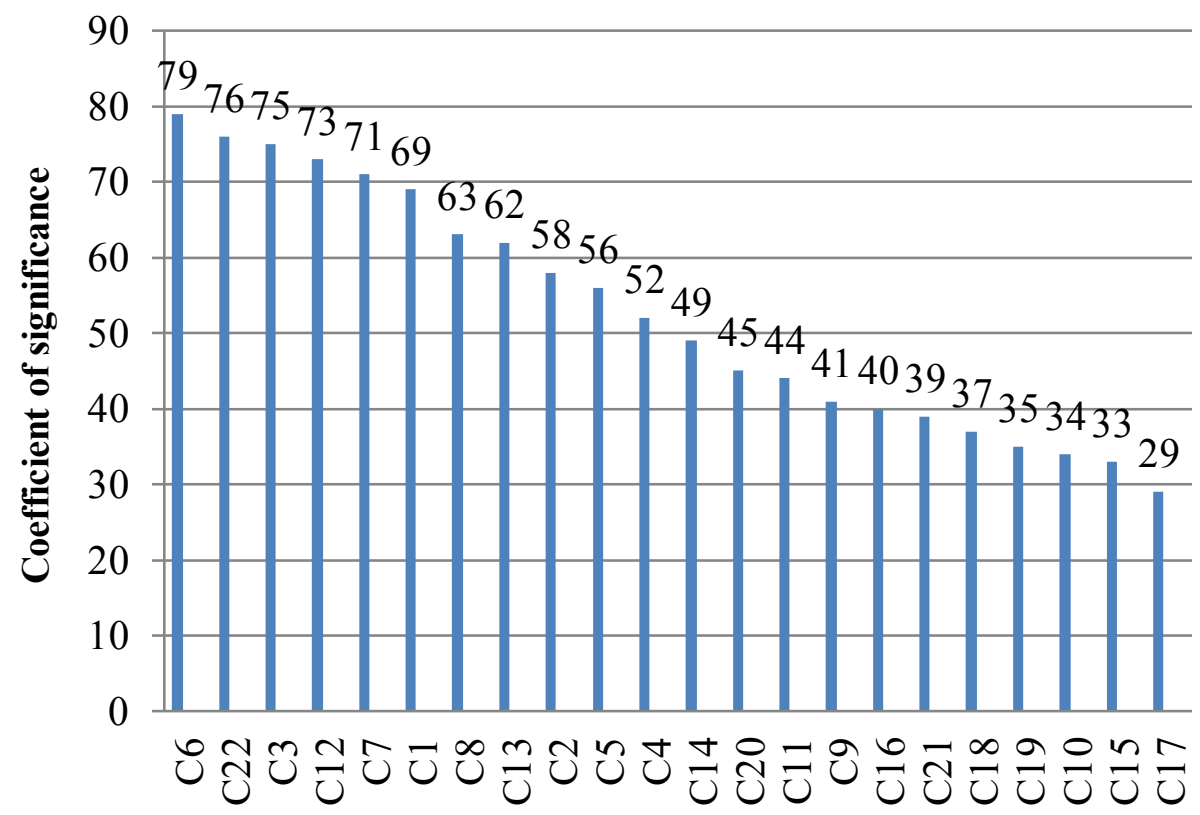

Symbol of factor

Fig. 1. Ranking of destabilizing factors depending on significance.

As an example shown in figure 2 , the destabilizing factor indicated by $\mathrm{C}_{6}$ shows that the number of responses giving this risk $100 \%$ significance is 40 out of 73 , and giving $75 \%$ significance is 15 out of 73 and etc.

The factor is a symbol $\mathrm{C}_{6}$ Suddenly interrupted funding

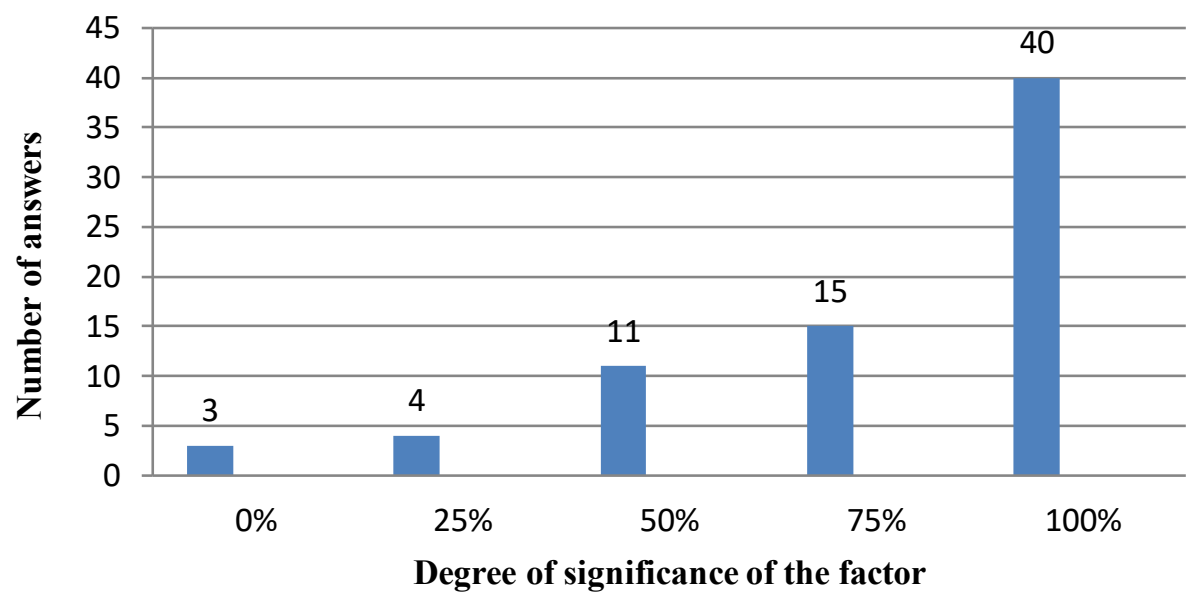

Fig. 2. The degree of significance of the factor 


\section{Results}

One of the problems of organizing the renovation process is that most of the facilities are in close proximity to other buildings, communications, roads, cultural monuments, etc. The planning of work on building reconstruction is often complicated by outdated methods of preparing documentation that certifies the rights of participants in the process of transforming territories into federal and municipal land plots. Norms and rules for the participation of management companies in the exploitation of lands on which renovation objects are located are not always defined.

Departmental disunity, the need to participate in this work of local governments, investors, the population, many organizations and enterprises of different forms of ownership make this process even more difficult. In addition, special attention should be paid to linking the adopted decisions with innovations in housing policy and in the system of transport and social and infrastructure services to residents.

The system approach to every concrete house, quarter, micro district is important. To date, there is practically no developed scientific, methodological and regulatory framework for analyzing, evaluating and selecting rational options for organizational and technological solutions in the development of renovation projects.

Essential help in optimizing this activity can be the application of special methods of planning, modeling and analysis, based on the extensive use of computer technology.

Obviously, the most important factor influencing the choice of organizational and technical solutions (OTS) is the constraint factor. This is "... the conditions of the existing urban development, suggesting the presence of spatial obstacles on the construction site and the adjacent territory, the restriction on the width, length, height and depth of the working area and underground space, the location of construction machinery and vehicles, the increased degree of construction, Ecological, material risk and, accordingly, enhanced security measures for those working in the construction industry and the living population "[7].

A competent analysis of this factor, carried out at the early stages of preparation of renovation projects, helps to choose the right solutions and, thereby, to reduce costs, reduce deadlines, improve the quality and safety of construction (Figure 3).

The proposed algorithm of analysis is based on the consideration of the constraint factor as an array of effects of individual "objects of influence" on the relevant "subjects of influence" [8] (Kiselev AA, 2010, Figure 4).

The main significant "objects of influence" (OI):

- operated buildings and structures;

- roads;

- existing communications.

"Subjects of influence" (SI) - aspects of organizational and technical solutions, the implementation of which is limited to "objects of influence." The main ones are:

- the boundaries of the construction site;

- the form of the three-dimensional organization of building (morphological type);

- placement and use of construction and lifting equipment.

Each object of renovation characterizes a unique set of OI and SI.

The result of the analysis of the effect of each OI on each SI is conveniently recorded in the form of a matrix (Figure 5).

The unit in the matrix means the presence of the effect of OIi on the corresponding SIj, and zero means its absence.

Having excluded the links OIi - SIj with "zero" influence, we pass to the analysis of significant "single" effects. 


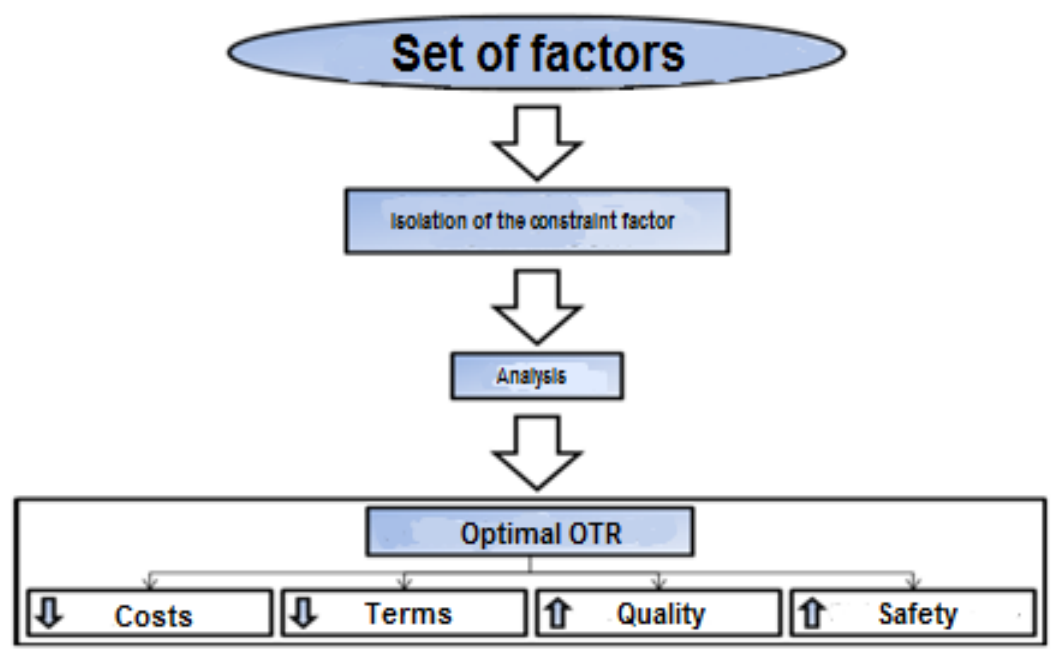

Fig. 3. The choice of optimal OTS based on the analysis of the constraint factor

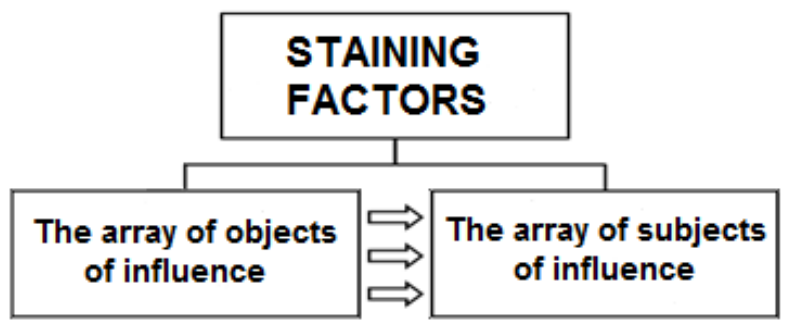

Fig. 4. Separation of the constraint factor into objects and subjects of influence

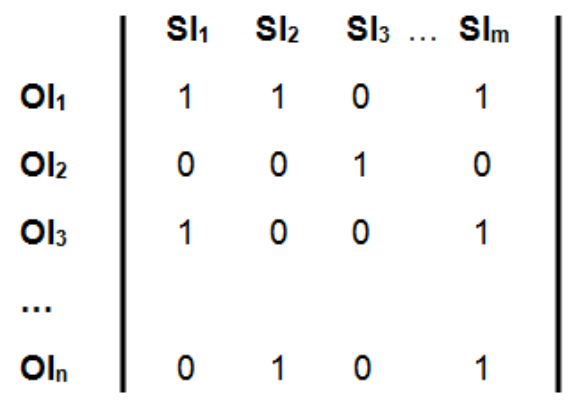

Fig. 5. Impact matrix

Since renovation projects by their definition imply a complete replacement of communications, infrastructure and roads (which in our case are objects of influence), it is important to divide the "eliminated" and "not eliminated" links.

The objects of the final analysis will be "single" "non-removable" links (Figure 6). 


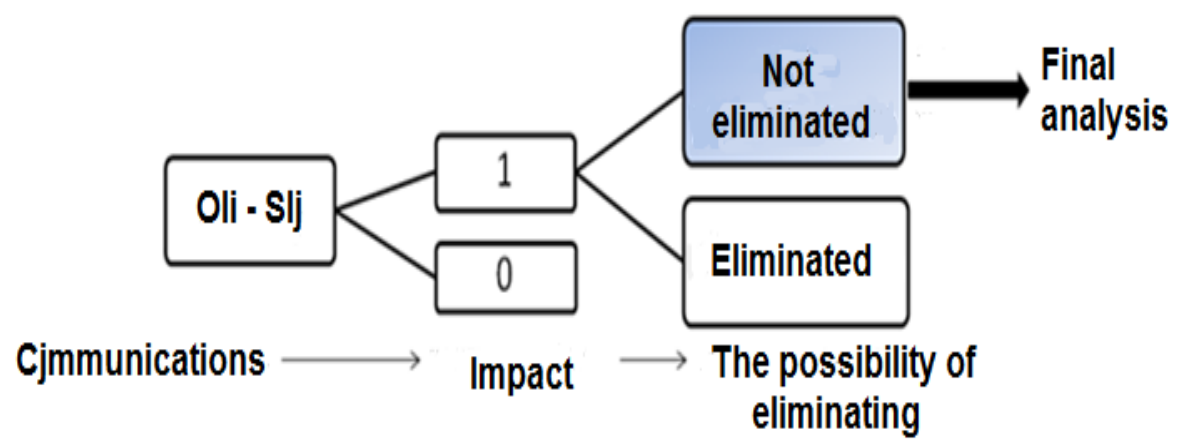

Fig. 6. Algorithm for analysis of relationships of the impact matrix

The data obtained during this analysis will help to find the most effective and optimal organizational and technological solutions reflected in the relevant sections of the renovation project, for example, in the development of a construction master plan, drawing up a calendar and network schedules for the production of works.

During the construction of objects the following main stages are distinguished:

- feasibility study;

- design of construction preparation and construction;

- implementation of preparation for the construction of the facility;

- construction of the facility;

- mastering the constructed object.

The development of construction requires an extensive increase in the pace and scope of works of the preparatory phase of construction (PPC), which is decisive in relation to all subsequent stages of the life cycle of a newly constructed or reorganized building project. Methods and methodologies for the development of design solutions for PPC and their quality significantly affect the engineering, technical and economic indicators of the processes of construction. Errors and miscalculations at the design stage of PES with high probability lead to emergence of contingencies, the liquidation of which requires additional labor, material and financial resources in unpredictable volumes.

One of the important criteria of PPC and the construction industry as a whole is organizational and technological reliability (OTR), one of the aspects of which is the consideration of specific features of organizational and technological processes for the construction of a particular facility (the personification of the model of its OTR).

Evaluation of design solutions requires:

- introduction of step-by-step modular consideration (discretization) of organizational and technological processes (works);

- taking into account the specific features of the implementation of the organizational and technological work of PES;

- the ranking of technological processes as their degree of automation increases.

All this allows us to propose a model for a multivariate analysis of the risks of implementing PPC project solutions and minimizing their consequences. The model is a set of eight stages of assessing the risks of the implementation of the design solution of PPC, that is, taking into account input and output criteria obtained at previous stages or defined for future stages of the model:

1. The risks inherent in PPC;

2. Reliability of technological processes of PPC;

3. Risk diagnostics;

4. Means of automation of processes;

5. Methodologies for achieving the required accuracy of results; 
6. Means of interpretation of diagnostic results;

7. The means to ensure the reliability of the main processes as algorithms to prevent the risks of the technological processes of the servicing subsystems to ensure the reliability of the main processes;

8. Sledging (documenting and archiving), forming a database of functioning.

\section{Discussion}

The analysis showed that the normative and directive documents of the Russian Federation, domestic and foreign researchers for the synthesis of design solutions and technologies for their implementation in automated systems of PES recommend using as a base model a human-machine (natural-artificial) functional system "man-technology-environment, TTE "[1].

Synthesis of design solutions is possible with step-by-step modular examination of organizational and technological processes. Application of the model of modular (discrete) structuring of organizational and technological processes of PPC provides an increase in the complex reliability of the technological process of the TTE system.

The cycle of "life" of the technological process in the TTE system is a cycle of synthesis of the design solution and consists of three "sistemokvantov" (the term of Sudakov K.V.) Qn, Qfa and Qbz [9].

Qbz is structured into three components (Qdm, Qnpz and Qpa).

Qn and Qfa are respectively the areas of normative work and the "failure" of the TTE system with respect to the $Q$ parameter.

Qbz is the "buffer zone, BZ", in which the TTE system regularly implements its regulatory functions, but, in the absence of corrective actions, it is guaranteed to pass to Qfa (inaction leads to irreversible consequences).

Qdm is the area of diagnostics and monitoring in the BZ, fixing the disturbing effect, which can bring the TTE system to the Qfa area (to create an abnormal situation) or to identify the tendency of the deviation of the values of the parameter $\mathbf{Q}$ in the $\mathbf{Q f a}$ domain.

Qnps is the area of the algorithm for preventing an abnormal situation (the transition of the values of the parameter $\mathbf{Q}$ to the Qen domain);

Qpa is the local implementation area of the algorithm for preventing an abnormal situation.

An important aspect of the global notion of "reliability" is complex reliability. For the TTE system, this is the average quadratic value of the reliability of each component of the TTE system (human, technical and environmental reliability).

Diagnosis of the current state of the reliability of the operation of the TTE system, monitoring of changes in this state and the impact on this state represent a closed sequence (cycle) of the processes performed, in which the end point of the implementation of the Qnen system and the beginning of the realization of the Qn are taken as the "beginning" or "cycle break point" when it is linearly mapped.

When investigating complex reliability by two parameters, the boundaries of the transition between system-quanta and their components are the achievement by either of the two parameters of the threshold value.

Evaluation of the operation of the TTE system by two parameters is not always sufficient. If it is necessary to evaluate the complex reliability for more than two parameters or to enter an additional parameter to evaluate the implementation of the algorithm for preventing an abnormal situation in two parameters (i.e., creating a system to prevent an abnormal situation for the algorithm being implemented), it is advisable to use the Radishchev-Memke drawing.

An important aspect of the synthesis and analysis of the design solution is the 
evaluation of its rationality by significant criteria (parameters) determined by the expert group. The design solution is rational if the value of its critical parameters is in the allowable range of values. Allowable and unacceptable threshold values of the selected parameters are advisable to represent in the matrix form $(\mathbf{R Z}, \mathbf{y})$.

Comparing the values of the critical parameters of the design solution $\mathbf{U}(\mathbf{p})$ with the matrix RZ, $\mathbf{y}$, we can form a conclusion about the rationality of the design solution. Comparison of the last row of the matrix RZ, $\mathbf{y}$ with each of the preceding rows by the criterion of "proximity" Zhuravlev Yu.I. Then it is possible to calculate the degree of correlation of the design solution with the threshold values of the critical parameters.

If the synthesized design solution admits risks but is rational, they design a model of an automated system for compensation of risks of the design solution of the PPC based on synthesis and analysis data.

\section{Conclusions}

When designing design solutions and testing in operating conditions, the following conclusions were made:

1. The analysis of the theory and practice of evaluation, sampling and synthesis in the process of designing and implementing the preparatory stage of the renovation of territories revealed a significant demand for the development of methods and models for the analysis and synthesis of such design solutions that compensate for the risks of performing organizational and technological construction processes and develop models of automated systems on their basis;

2. The proposed model allows to take into account the specific features of the performance of the organizational and technological works of the preparatory stage, to rank the technological processes as the degree of automation increases;

3. The proposed model of modular structuring of organizational and technological processes of the preparatory stage of the renovation of the territory provides the synthesis of organizational solutions and technologies for their implementation (the model of the life cycle of the technological process with the allocation of a specific buffer zone);

4. The proposed concept of analysis and synthesis of design solutions for the organizational and technological work of the preparatory phase in the CAD PPC allows to develop a model of an automated system for compensation of risks;

5. The developed models are used in the synthesis and analysis of design solutions for the preparation of construction, the implementation of preparatory works for renovation in the construction of temporary local roads in the territory of the Republic of TUVA and the Vologda region.

The realized rational variant of the design solution ensured the reduction of the prime cost and the reduction of the terms of the preparatory works for the renovation of housing construction projects in the Irkutsk region, taking into account seismic uncertainty. Modern theoretical concepts (not related to business and employment problems) combine the last two spheres into one "information and energy" one based on the well-known functional dependence of the "bit" and "joule" units (according to Felker). The proposed models can be adapted to the synthesis and analysis of design solutions for other stages of housing and industrial construction, also of multi-criteria analysis of quality in high rise construction. 


\section{References}

1. A.A. Volkov, V.O. Chulcov, R.R. Kazaryan, V.A. Fachratov, O.N. Kyzina, R.K. Gazaryan, AMM, 580-583, 2281-2284 (2014). DOI: 10.4028 / www.scientific.net / AMM.580- 583.2281.

2. A.A. Volkov, V.O. Chulkov, R.R. Kazaryan, R.K. Gazaryan, AMM, 584-586, 26852688 (2014). DOI: 10.4028 / www.scientific.net / AMM.584-586.2685.

3. O. Anishchenko, V. Kukhar, V. Agarkov, A. Vorobeva, E3S Web Conf., 135, 01002 (2019). DOI: https://doi.org/10.1051/e3sconf/201913501002.

4. A. Iglovikov, A. Motorin, E3S Web Conf., 135, $01003 \quad$ (2019). DOI: https://doi.org/10.1051/e3sconf/201913501003.

5. A. Iglovikov, A. Motorin, E3S Web Conf., 135, $01004 \quad$ (2019). DOI: https://doi.org/10.1051/e3sconf/201913501003.

6. A. Lastovka, T. Danchenko, N. Klinduh, M.Berseneva, E3S Web Conf., 135, 01048 (2019). DOI: https://doi.org/10.1051/e3sconf/201913501048.

7. E. Voitov, Yu. Skolubovich, V. Kravchenko, T. Khalturina, E3S Web Conf., 135, 01055 (2019). DOI: https://doi.org/10.1051/e3sconf/201913501055.

8. A. Lastovka, T. Danchenko, N. Klinduh, M.Berseneva, E3S Web Conf., 135, 01048 (2019). DOI: https://doi.org/10.1051/e3sconf/201913501048.

9. A.A.Volkov, V.O.Chulkov, R.R.Kazaryan, S.A.Sinenko, AMM, 584-586, 2681-2684 (2014). DOI: 10.4028/www.scientific.net/AMM.584-586.2681.

10. K. Yu. Losev, V. O. Chulkov, R.R. Kazaryan, MSE, 463(3), 032085 (2018). DOI: 10.1088 / 1757-899X / 463/3/032085.

11. R.R. Kazaryan, MATEC Web Conf., 239, 02006 (2018). DOI: https://doi.org/10.1051/matecconf/201823902006.

12. S. Sinenko, B. Zhadanovsky, V. Obodnikov, E3S Web Conf., 110, 01036 (2019). DOI: https://doi.org/10.1051/e3sconf/201911001036.

13. R.R. Kazaryan, MATEC Web Conf., 193, 01009 (2018).

14. R.R. Kazaryan, MATEC Web Conf., 193, 04023 (2018).

15. R.R. Kazaryan, MATEC Web Conf., 239, 02006 (2018).

16. R.R. Kazaryan, MATEC Web Conf., 170, 05001 (2018). 